\title{
Combined Pharmacological and Electrophysiological Dissociation of Familiarity and Recollection
}

\author{
Tim Curran, ${ }^{1}$ Casey DeBuse, ${ }^{1}$ Brion Woroch, ${ }^{1}$ and Elliot Hirshman ${ }^{2}$ \\ ${ }^{1}$ Department of Psychology and Center for Neuroscience, University of Colorado, Boulder, Colorado 80309-0345, and 2Department of Psychology, George \\ Washington University, Washington, DC 20052
}

\begin{abstract}
Dual-process theories of recognition memory hypothesize separate underlying familiarity and recollection processes, but the necessity of multiple processes is debated. Previous research has suggested that scalp-recorded event-related brain potentials (ERPs) may index the activity of separate familiarity and recollection processes. Other research indicates that the amnestic drug midazolam impairs recollection more than familiarity. Here, we used a convergent pharmacological and electrophysiological approach to manipulate and monitor human brain activity and provide evidence for separate processes. Midazolam selectively influenced the putative ERP-correlate of recollection but not the putative ERP-correlate of familiarity. Under control conditions (saline), subjects' accuracy correlated with the recollection-related but not the familiarity-related ERP component, suggesting that recollection was dominant in driving memory. The opposite pattern was observed under midazolam administration, suggesting that when recollection fails, subjects may leverage familiarity to compensate. Thus, in contrast to perspectives holding that familiarity represents the default process, these results suggest that recollection was dominant until its impairment unveiled the influence of familiarity.
\end{abstract}

Key words: EEG; ERP; dual process; recognition memory; benzodiazapine; psychopharmacology

\section{Introduction}

People often experience the feeling that something or someone is familiar, without recollecting any associated details to further specify their memory. According to dual-process theories of recognition memory, such experiences are the phenomenal consequences of separate familiarity and recollection processes (Jacoby, 1991; Reder et al., 2000; Yonelinas, 2002; Norman and O'Reilly, 2003; Rugg and Yonelinas, 2003; Malmberg et al., 2004a). Despite the popularity and influence of dual-process theories, they are controversial because of the difficulty in obtaining separate empirical estimates of recollection and familiarity and the greater parsimony associated with single-process theories (for review, see Yonelinas, 2002).

Midazolam, an amnesia-inducing benzodiazepine, has been used to dissociate recollection from familiarity (Hirshman et al., 2002). When subjects were asked to subjectively report whether their recognition judgments were based on "remembering" (i.e., recollection) or "knowing" (i.e., familiarity without recollection), the results of Hirshman et al. suggested that midazolam affected recollection more than familiarity. Furthermore, its affects on recognition memory for high- versus low-frequency

Received Sept. 26, 2005; revised Jan. 9, 2006; accepted Jan. 10, 2006.

This work was supported by a General Clinical Research Center grant from the National Institutes of Health (NIH)-National Center for Research Resources (M01RR00051) and NIH Grant MH64812. We thank the staff of the Boulder General Clinical Research Center for medical assistance; Greg Carey for statistical advice; Michael Frank, Erika Nyhus, and Nicole Speer for helpful comments; and Daniel Blum, Sophie Boddington, John Capps, Debra Chase, Danielle Germain, Jane Hancock, Christel Taylor, Elan Walsky, and Brent Young for help with subject testing.

Correspondence should be addressed to Tim Curran, Department of Psychology, 345 UCB, University of Colorado, Boulder, C0 80309-0345. E-mail: tcurran@colorado.edu.

DOI:10.1523/JNEUROSCI.5370-05.2006

Copyright $\odot 2006$ Society for Neuroscience $\quad$ 0270-6474/06/261979-07\$15.00/0 words were consistent with dual-process accounts of the wordfrequency effect (Joordens and Hockley, 2000; Reder et al., 2000).

Others have promoted the use of neuroimaging to advance dual-process theories (Rugg and Yonelinas, 2003). Functional magnetic resonance imaging studies have suggested that recollection may involve the hippocampus, parietal, and prefrontal cortex (Eldridge et al., 2000; Wheeler and Buckner, 2004; Yonelinas et al., 2005), whereas familiarity may involve the medial temporal cortical areas that surround the hippocampus (Henson et al., 2003; Gonsalves et al., 2005). Event-related brain potentials (ERPs) recorded from scalp electrodes have provided further evidence for separate recollection and familiarity processes. When recorded during a recognition memory test, ERPs reliably differ between correctly classified old and new items starting $\sim 300 \mathrm{~ms}$ after stimulus onset (Friedman and Johnson, 2000; Mecklinger, 2000). Several studies have distinguished between mid-frontal ERP old/new difference peaking at $\sim 400 \mathrm{~ms}$ ("FN400 old/new effect") and a parietal old/new difference peaking at $\sim 600 \mathrm{~ms}$ ("parietal old/new effect"). It has been suggested that the FN400 is related to familiarity, whereas the parietal old/new effect is related to recollection (Rugg et al., 1998b; Curran, 2000; Düzel et al., 2001; Nessler et al., 2001; Curran and Cleary, 2003; Rugg and Yonelinas, 2003; Nessler et al., 2005; Curran et al., 2006), although different perspectives exist (Olichney et al., 2000; Yovel and Paller, 2004).

The primary goal of the present research was to use a convergent electrophysiological (ERP) and psychopharmacological (midazolam) approach to further our understanding of recollection and familiarity processes. Subjects studied 120 words after an injection of either saline or midazolam. Approximately $70 \mathrm{~min}$ later, ERPs were recorded during a recognition memory test with 
old and new words. Based on previous dual-process interpretations of midazolam (Hirshman et al., 2002) and ERP effects (Rugg et al., 1998b; Curran, 2000; Nessler et al., 2001, 2005; Curran and Cleary, 2003; Rugg and Yonelinas, 2003), we hypothesized that midazolam would affect the parietal ERP old/new effect (putatively related to recollection) more than the FN400 ERP old/new effect (putatively related to familiarity).

\section{Materials and Methods}

Subjects. Twenty-three University of Colorado students participated in the experiment for payment. Three subjects were excluded from the final analyses for falling asleep $(n=1)$ or failing to respond to too many study words $(>20 \% ; n=2)$ during the midazolam session. Of the 20 remaining subjects included in the analyses, 13 were female [age: mean (MN), 21 years; range, $18-28$ years]. All subjects were right-handed, native English speakers and weighed $<83 \mathrm{~kg}$ ( $183 \mathrm{lbs}$, so as not to exceed the maximum midazolam dosage). Each subject participated in two sessions (once with saline and once with midazolam, double-blind), which each lasted $\sim 2.5-3$ h. Before each session, a urine sample was collected to test for toxicology and pregnancy, and a breathalyzer was used to test for alcohol intoxication. The toxicology screen followed a "Drugs of Abuse" profile to screen for $\Delta 9$-tetrahydrocannabinol, opiates, amphetamines, cocaine, phencyclidine, barbiturates, benzodiazepines, and (+)-3,4methylenedioxymethamphetamine. All procedures were approved by the Human Research Committee of the University of Colorado, in accord with federal guidelines for protection of human subjects.

Stimuli. Stimuli were 480 low-frequency (MN, 1.26; range, 1-2 counts per million) (Kucera and Francis, 1967), four to seven letter English words. The words were divided randomly into four 120 -word sets that appeared equally often in each condition (old/new-by-midazolam/saline).

Design and procedure. A two-by-two within-subjects design manipulated memory status of words (old/new) and drug condition (midazolam/saline). Subjects completed one session with midazolam and one session with saline (double-blind), with order counterbalanced between subjects. Sessions averaged 9.3 d apart (range, 7-26).

Sessions were run at the General Clinical Research Center at the University of Colorado at Boulder. Qualified medical staff and cardiopulmonary resuscitation equipment were available throughout the session. After completing a consent form and brief medical screening, an intravenous catheter was inserted, and participants were administered an injection of either $0.03 \mathrm{mg} / \mathrm{kg}$ of body weight of midazolam diluted to a total volume of $10 \mathrm{ml}$ or $10 \mathrm{ml}$ of saline. The injection was given over 2 min, with a maximum dose of $2.5 \mathrm{mg}$ (thus, maximum weight of participants was $83 \mathrm{~kg}$ ). Shortly after the injection (MN, $5.43 \mathrm{~min})$, subjects studied 120 words, followed by $\sim 70$ min of interpolated activity including several cognitive tasks and Sensor Net setup (MN, $70.8 \mathrm{~min}$ ), followed by the 240 word recognition memory test. The interpolated activity included procedural learning and name recall tasks that are reported previously (Frank et al., 2006) as well as a two-back working memory task given immediately before the recognition task. $t$ tests indicated no significant differences in the timing of these events between the saline and drug conditions. The plasma half-life of midazolam is $1-4 \mathrm{~h}$ (Feldman et al., 1997), but we assume its affects on memory are primarily limited to the encoding phase. Previous research has shown that midazolam impairs memory when given during study, but not when given during test (Polster et al., 1993).

Before the actual study list, subjects completed a 10 word practice list. The 120-word study list was divided into four 30-word blocks with selfpaced rest breaks in between. The beginning and end of each block were flanked by two nontested words as primacy and recency buffers. Each word was displayed in the center of a computer monitor for $4 \mathrm{~s}$, with a $1 \mathrm{~s}$ interword interval. Subjects were informed that their memory for the words would be tested later and were asked to rate the pleasantness of each word on a four-point scale. If the subject failed to make a pleasantness rating within $4 \mathrm{~s}$, the computer beeped until a response was made.

Before the actual recognition test list, subjects completed a 10 word practice list. The 240 word test lists was divided into 12 20-word blocks with self-paced breaks in between. Each trial began with a randomly determined 500-1000 ms fixation point, followed by test-word presentation for $2000 \mathrm{~ms}$. Subjects were instructed to withhold their response until a question mark appeared immediately after test-word offset. Responses were delayed in this manner to minimize response-related ERP effects. Responses were made by pressing keys on a response box with the first finger of each hand. Assignment of hands to old/new responses were counterbalanced across subjects. A $500 \mathrm{~ms}$ intertrial interval followed each response.

EEG/ERP recording and analysis. During the recognition memory task, scalp voltages were collected with a 128 channel Geodesic Sensor Net (Tucker, 1993) connected to an AC-coupled, 128 channel, high-input impedance amplifier (200 M $\Omega$; Net Amps; Electrical Geodesics, Eugene, OR). Amplified analog voltages $(0.1-100 \mathrm{~Hz}$ bandpass) were digitized at $250 \mathrm{~Hz}$. Individual sensors were adjusted until impedances were $<50 \mathrm{k} \Omega$. The EEG was digitally low-pass filtered at $40 \mathrm{~Hz}$. Trials were discarded from analyses if they contained incorrect responses, eye movements (electrooculogram over $70 \mu \mathrm{V}$ ), or $>20 \%$ of channels were bad (average amplitude over $100 \mu \mathrm{V}$ or transit amplitude over $50 \mu \mathrm{V}$ ). Individual bad channels were replaced on a trial-by-trial basis with a spherical spline algorithm (Srinivasan et al., 1996). EEG was measured with respect to a vertex reference $(\mathrm{Cz})$, but an average-reference transformation was used to minimize the effects of reference-site activity and accurately estimate the scalp topography of the measured electrical fields (Picton et al., 1995; Dien, 1998a). The average reference was corrected for the polar average reference effect (Junghöfer et al., 1999).

ERPs were obtained by stimulus-locked averaging of the EEG recorded in each condition. ERPs were baseline-corrected with respect to a $100 \mathrm{~ms}$ prestimulus recording interval. Incorrect trials and words that were missed during the study task were excluded. The mean number of trials/ condition/subject was: midazolam/new, 84; midazolam/old, 60; saline/ new, 90; saline/old, 91. The minimum number of trials/condition/subject was: midazolam/new, 41; midazolam/old, 28; saline/new, 53; saline/ old, 66 .

Statistical analysis. ERP analyses were guided by previous work, showing that FN400 old/new effects typically peak between 300 and $500 \mathrm{~ms}$ over superior, frontal regions, and parietal old/new effects typically peak between 500 and $800 \mathrm{~ms}$ over parietal regions (Curran, 2000, 2004; Curran and Cleary, 2003; Curran and Dien, 2003). Initial analyses focused on separate regions of interest shown in Figure 1 for the FN400 [left, anterior, superior (LAS) and right, anterior, superior (RAS) regions] and parietal effects [left, posterior, superior (LPS) and right, posterior, superior (RPS) regions]. Repeated-measures ANOVA included drug condition (saline, midazolam), memory status (old, new), and hemisphere (left, right) as independent variables. The dependent measure was mean amplitude averaged across all channels within each region of interest for each condition. Mean amplitude was calculated from 300 to $500 \mathrm{~ms}$ for the FN400 and from 500 to $800 \mathrm{~ms}$ for the parietal effect. The complete topography of the ERP effects were examined by including a broader sample of regions, as shown by the eight dark electrode clusters in Figure 1 (Curran, 2000, 2004; Curran and Cleary, 2003). Mean amplitude within each region was entered into a drug-by-old/new-by-hemisphereby-anterior/posterior (AP)-by-inferior/superior (IS) ANOVA. Again, separate ANOVAs were conducted from 300 to 500 and 500 to $800 \mathrm{~ms}$. Finally, the old/new differences were entered into a spatial Principle Components Analysis (PCA) using Dien's PCA toolbox, obtainable on request from jdien@ku.edu (Dien, 1998b). The spatial PCA treated the 129 channels as variables with 15,000 observations: 20 subjects-by-two conditions-by-375 time points ( -100 to $1500 \mathrm{~ms}$, sampled at $250 \mathrm{~Hz}$ ). The covariance matrix was the measure of association, orthogonal varimax rotation was used to isolate spatially independent sources of variability, and a scree test was used to determine the number of factors retained.

\section{Results}

During the encoding task, subjects were slower to make pleasantness ratings in the midazolam $(\mathrm{MN}, 2301 \mathrm{~ms})$ than saline $(\mathrm{MN}$, $1986 \mathrm{~ms})$ condition $\left(t_{(19)}=5.05\right.$; SE, 62.30; $\left.p<0.001\right)$. Furthermore, failures to respond to study-list words were more frequent 


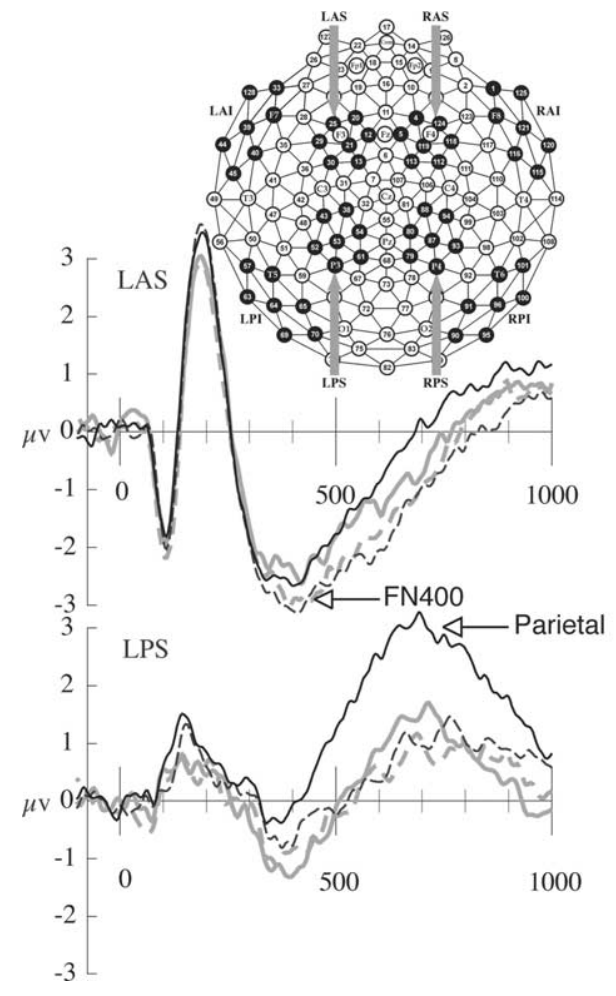

The parietal ERP effects were analyzed within superior, posterior regions of interest (Fig. 1, LPS and RPS) from 500 to 800 ms. Main effects of drug, old/new, and hemisphere were each significant $(p<$ 0.05 ) as well as interactions of old/new with drug and old/new with hemisphere. Critically, the old/new-by-condition interaction $\left(F_{(1,19)}=4.46\right.$; MSE, $2.30 ; p<$ $0.05)$ indicated that the parietal old/new difference was significant after saline $(F=$ 17.22; $p<0.001)$ but not midazolam $(F=$ 1.35) (Fig. 2, right). The drug-by-old/newby-hemisphere interaction indicated that drug influences on the old/new difference were more pronounced over the left than right hemisphere $\left(F_{(1,19)}=11.67\right.$; MSE, $0.17 ; p<0.01)$.

The complete topography of the memory effects was examined by including a broader sample of regions, as shown by the eight dark electrode clusters in Figure 1. Tables 1 (500-800 ms) and 2 (300-500 $\mathrm{ms}$ ) show all significant effects involving drug or memory status (old/new). Topographic maps of the old/new differences are shown in Figure 3. We will first describe the 500-800 ms parietal effects, which have implications for interpretation of the earlier effects (Table 1). The overall

Figure 1. ERP waveforms. Grand-averaged ERPs are shown for each condition, averaged within the regions of interest used in the primary analyses. Region locations are shown in the Geodesic Sensor Net diagram.

under midazolam $\left(\mathrm{MN}, 5.50\right.$ vs $1.05 ; t_{(19)}=5.31$; SE, $0.84 ; p<$ $0.001)$. Thus, ERP analyses excluded words that were missed on the study list.

Performance on the spatial two-back, working-memory task provided an estimate of cognitive ability, immediately before the recognition test. Drug-by-condition (target, nontarget) ANOVAs were done with both accuracy and response time (RT) on accurate trials. Accuracy did not significantly differ between the midazolam $(\mathrm{MN}, 0.88)$ and saline $(\mathrm{MN}, 0.90)$ conditions $(F<1)$. Overall RT did not differ between conditions [MN: midazolam, $636 \mathrm{~ms}$; saline, $612 \mathrm{~ms} ; F_{(1,19)}=1.34$; mean squared error (MSE), 8514; $p>0.10$ ] but the drug-by-condition interaction was significant $\left(F_{(1,19)}=4.53\right.$; MSE, $\left.835 ; p=0.047\right)$. The interaction suggested that drug effects were larger for targets (MN: midazolam, $624 \mathrm{~ms}$; saline, $586 \mathrm{~ms}$ ) than nontargets (MN: midazolam, $648 \mathrm{~ms}$; saline, $638 \mathrm{~ms}$ ), with only the difference for targets being significant $(p<0.01)$.

Recognition memory performance was profoundly impaired by midazolam. Midazolam lowered hit rates $(\mathrm{MN}, 0.60$ vs 0.90 ; $t_{(19)}=7.45$; SE, $\left.0.04 ; p<0.001\right)$ and increased false alarm rates $\left(\mathrm{MN}, 0.18\right.$ vs $\left.0.12 ; t_{(19)}=2.51 ; \mathrm{SE}, 0.03 ; p<0.05\right)$. Signal detection analysis indicated that midazolam reduced discrimination $\left(d^{\prime} ; \mathrm{MN}, 1.29\right.$ vs $2.61 ; t_{(19)}=9.48 ;$ SE, $\left.0.14 ; p<0.001\right)$. Additionally, response bias was more conservative after midazolam $(\mathrm{MN}$, $0.38)$ than saline $\left(\mathrm{MN},-0.05 ; t_{(19)}=4.67\right.$;E, $\left.0.09 ; p<0.001\right)$.

The FN400 ERP effects were analyzed within superior, anterior regions of interest (Fig. 1, LAS and RAS) from 300 to $500 \mathrm{~ms}$. Only the old/new difference was significant, with more negative amplitudes for new $(\mathrm{MN},-2.59 \mu \mathrm{V})$ than old $(\mathrm{MN},-2.24 \mu \mathrm{V})$ words $\left(F_{(1,19)}=9.20\right.$; MSE, $\left.0.51 ; p<0.01\right)$. No drug effects or interactions approached significance (all $F<1$ ), including the critical drug-by-old/new interaction $(F<1$; MSE, 0.60) (Fig. 2, left). distribution of the $500-800 \mathrm{~ms}$ parietal old/new difference is captured by the old/new-by-hemisphere-by-AP-by-IS interaction. As is typical, parietal old/new differences were largest within the left, posterior, superior region. Furthermore, several significant three-way interactions between drug condition, old/new, and each of the spatial factors were significant. These generally indicated that amplitudes to old words were more positive for saline than midazolam over the left hemisphere, posterior channels, and superior channels (Fig. 3, 500-800 ms topographies).

For the FN400 (300-500 ms) (Table 2), old/new differences interacted across inferior/superior such that they were only significant over superior regions. Contrary to the previous FN400 analysis, which was limited to anterior/superior regions, significant drug effects were observed, including two four-way interactions (Table 2, bottom). These interactions suggested that drug effects were observed for old items over left/superior and left/ posterior regions. As can be seen for the saline condition in Figure 3 , these analyses indicate that parietal old/new differences over left, posterior regions began within the 300-500 window. Conversely, frontal old/new differences remain similar between conditions within the later slices. Such temporal overlap between the FN400 and parietal old/new effects is not unusual (Curran, 2000, 2004; Curran and Cleary, 2003).

The initial ANOVAs indicated that the FN400 and parietal old/new differences may be better separated spatially than temporally. Therefore, the old/new differences were entered into a spatial PCA. A scree tested indicated retention of 21 factors, accounting for $90 \%$ of the variability. Of these, four primary factors each accounted for $>5 \%$ of the variance. These factors peaked at channels 61 (26\% of variance), 25 (11\%), $117(8 \%)$, and $8(12 \%)$ (see Fig. 1 for channel locations). As shown in Figure 4, the distributions of the first and second factors appear consistent with the parietal (Fig. 4b) and FN400 (Fig. 4a) old/new effects. Al- 

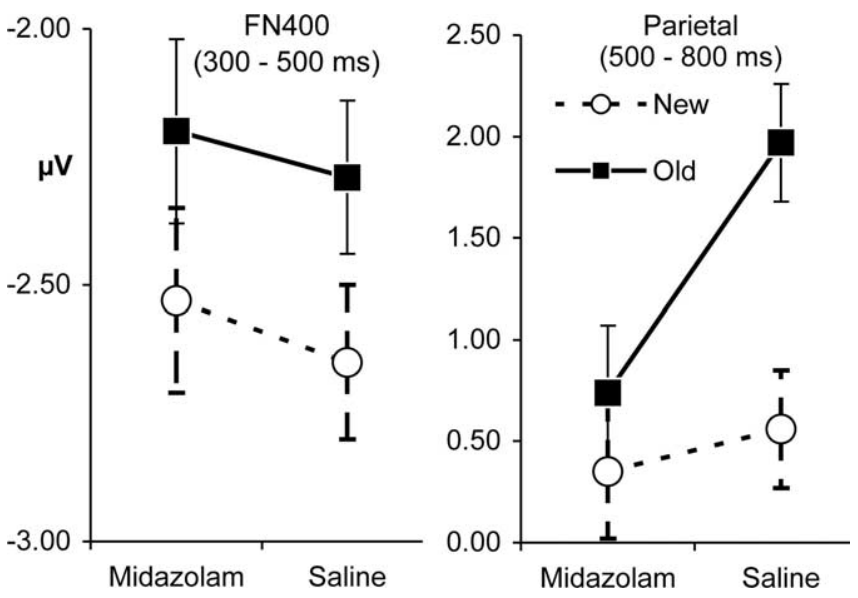

Figure 2. Mean amplitude of the FN400 and parietal ERP effects. FN400 amplitudes are computed across the LAS and RAS regions. Parietal amplitudes are computed across the LPS and RPS regions. Error bars are SE of old/new difference.

Table 1. Results of eight-region ANOVA from 500 to $800 \mathrm{~ms}$

\begin{tabular}{lcll}
\hline Effect & $F$ & MSE & $p<$ \\
\hline Old/new & 8.03 & 1.68 & 0.05 \\
Drug-by-Hm & 7.77 & 0.9 & 0.05 \\
ON-by-Hm & 10.31 & 0.64 & 0.01 \\
Drug-by-AP & 5.08 & 4.46 & 0.05 \\
ON-by-IS & 32.25 & 0.99 & 0.001 \\
Drug-by-ON-by-Hm & 8.16 & 0.2 & 0.01 \\
Drug-by-ON-by-AP & 4.14 & 0.98 & 0.06 \\
Drug-by-ON-by-IS & 8.14 & 1.13 & 0.01 \\
Drug-by-ON-by-Hm-by-IS & 9.62 & 0.06 & 0.01 \\
ON-by-Hm-by-AP-by-IS & 7.45 & 0.12 & 0.05 \\
\hline
\end{tabular}

ON, Old/new; Hm, hemisphere.

Table 2. Results of eight-region ANOVA from 300 to $500 \mathrm{~ms}$

\begin{tabular}{lccc}
\hline Effect & $F$ & MSE & $p<$ \\
\hline ON-by-IS & 9.22 & 0.38 & 0.01 \\
Drug-by-Hm-by-AP & 6.45 & 0.32 & 0.05 \\
Drug-by-ON-by-Hm-by-AP & 7.2 & 0.12 & 0.05 \\
Drug-by-ON-by-Hm-by-IS & 14.16 & 0.02 & 0.01 \\
\hline
\end{tabular}

ON, Old/new; Hm, hemisphere.

though the parietal factor scores were numerically larger for the saline than midazolam conditions from 500 to $800 \mathrm{~ms}$, this difference was not statistically significant $\left(F_{(1,19)}=1.71\right.$; MSE, 3.48; $p>0.10)$. As expected, the FN400 factor scores from 300 to 500 $\mathrm{ms}$ also did not differ between conditions $\left(F_{(1,19)}<1\right.$; MSE, 0.84).

A correlation analysis examined the relationship between these PCA factors and accuracy $\left(d^{\prime}\right)$ in each condition. The FN400 factor positively correlated with $d^{\prime}$ in the midazolam condition ( $r=0.42 ; p<0.05$; one-tailed) (Fig. $5 a)$ but not in the saline condition $(r=0.09)$. The parietal factor correlated more highly with $d^{\prime}$ after saline ( $r=0.33 ; p=0.08$; one-tailed) (Fig. $5 b$ ) than midazolam $(r=-0.27)$. For each factor separately, a mixedmodel analysis was conducted to determine whether the correlation between that factor score and $d^{\prime}$ interacted with drug condition. The drug-by-factor interaction was significant for the parietal factor (i.e., the slopes of two lines are significantly different in Fig. $5 b)\left(F\left(_{1,35.24)}=4.78 ; p<0.05\right)\right.$ but not for the FN400 factor $\left(F_{(1,21.75)}=1.13\right)$. Although not technically an outlier, removing the one subject with the highest saline factor score $(z=$ 1.64, circled in Fig. $5 b$ ) substantially increased the correlation in the saline condition ( $r=0.48 ; p=0.02$; one-tailed).

\section{Discussion}

Administration of midazolam before studying a list of words substantially impaired recognition memory $\sim 1.5 \mathrm{~h}$ later. By measuring ERPs during the recognition test, we obtained evidence consistent with the performance decrement being related to impaired recollection rather than familiarity. The frontal, 300$500 \mathrm{~ms}, \mathrm{FN} 400 \mathrm{old} / \mathrm{new}$ effect, putatively related to familiarity, was not significantly influenced by midazolam; but the 500-800 $\mathrm{ms}$ parietal old/new effect, putatively related to recollection, was eliminated by midazolam.

The necessity of the dual-process models has been challenged by demonstrations that single-process models are sufficient to explain results that purportedly support the dual-process perspective (Ratcliff et al., 1995; Donaldson, 1996; Hirshman and Master, 1997; Dennis and Humphreys, 2001; Dunn, 2004). For example, Malmberg et al. (2004b) simulated the midazolam results of Hirshman et al. (2002) with a single-process, familiaritybased memory model (Shiffrin and Steyvers, 1997) by merely assuming that midazolam resulted in the storage of noisier (i.e., less accurate) memory traces than the control (saline) condition. Furthermore, the subjective remember/know ratings were explained by assuming that familiarity underlies both remember and know judgments, but subjects set a higher decision criterion, requiring higher familiarity, for responding remember (Donaldson, 1996; Hirshman and Master, 1997; Dunn, 2004). The model of Malmberg et al. provided a good quantitative fit to the results of Hirshman et al., but it did not replicate all ordinal comparisons, so questions about the sufficiency of this model remain.

The present ERP results are consistent with a dual-process interpretation of the effects of midazolam. The frontal FN400 and parietal old/new effects were associated with distinct topographic patterns. Although scalp ERPs do not allow us to clearly identify the anatomical sources of these patterns, the presence of separate topographies associated with independent sources of variability (i.e., PCA results) is consistent with the existence of separate underlying brain sources (Picton et al., 2000). In principle, the effects of midazolam on memory might be simulated with a single-process model (Malmberg et al., 2004b), but the present ERP results strongly support a dual-process model whereby midazolam impairs recollection (indexed through the parietal old/ new effect) while sparing anatomically separate familiarity process(es) (indexed through the FN400 old/new effect). The distribution of midazolam-sensitive receptors might provide some insight into the anatomical locus of the affected recollection processes. Midazolam exerts its effects by increasing the binding of $\mathrm{GABA}$ to $\mathrm{GABA}_{\mathrm{A}}$ receptors. Although $\mathrm{GABA}_{\mathrm{A}}$ receptors are distributed widely throughout the brain (Montpied et al., 1988), their dense expression within the hippocampus (Evans and Viola-McCabe, 1996; Kobayashi et al., 2004, 2005) suggests that it might be a primary site of its amnestic effects (but see Reinsel et al., 2000). It has been demonstrated previously that, like the present midazolam effects, selective lesions of the hippocampus disrupt the parietal ERP recollection effect without affecting the FN400 familiarity effect (Düzel et al., 2001).

In addition to providing support for a dual-process interpretation of midazolam effects (Hirshman et al., 2002), the present results provide further support for the dual-process interpretation of the FN400 and parietal ERP effects (Rugg et al., 1998b; Curran, 2000; Nessler et al., 2001, 2005; Curran and Cleary, 2003; Rugg and Yonelinas, 2003). Previous studies have suggested that the parietal effect, but not the FN400 effect, correlates with memory performance (Olichney et al., 2000). This has raised questions 


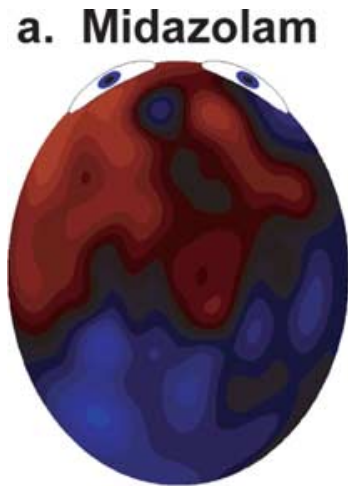

$300-400$

\section{b. Saline}

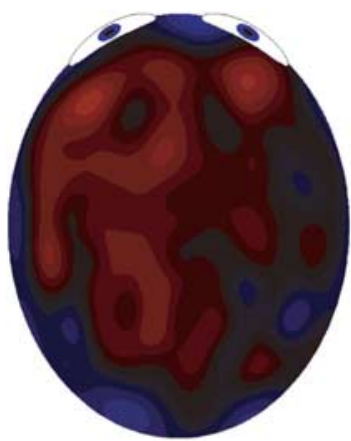

$300-400$

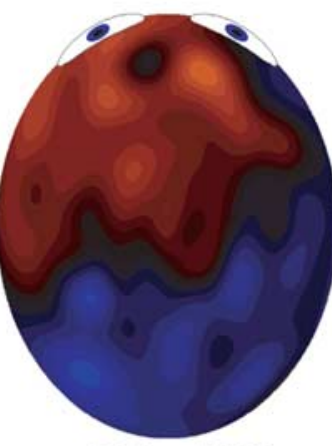

$400-500$

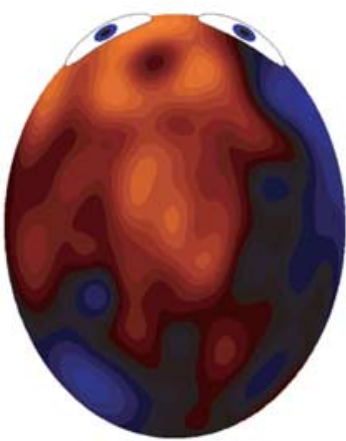

$500-600$

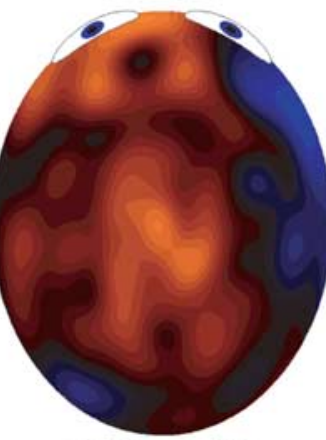

$600-700$

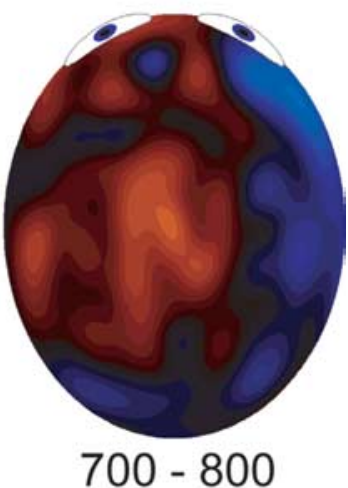

$700-800$

\section{$-2 \mu \mathrm{V}+2 \mu \mathrm{V}$}

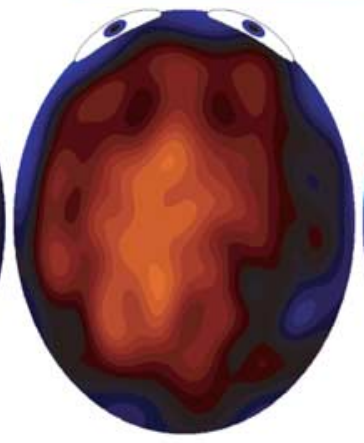

$400-500$

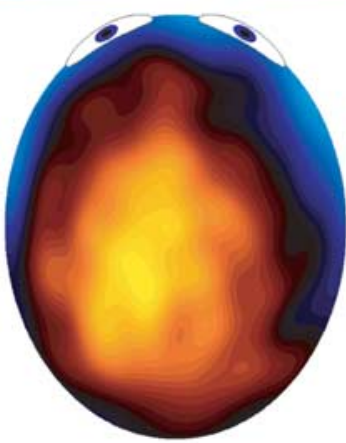

$500-600$

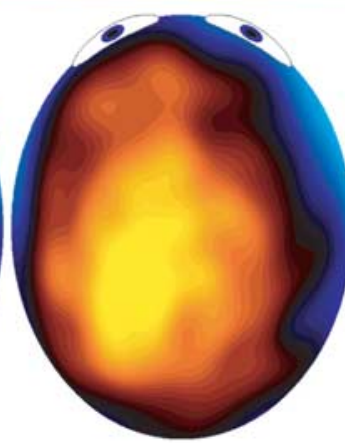

$600-700$

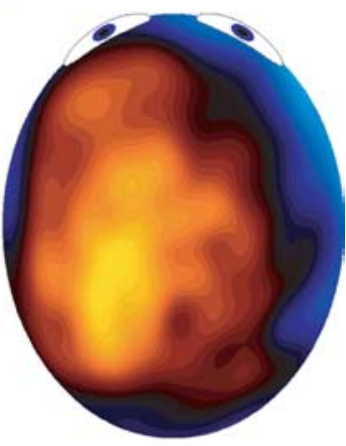

$700-800$

Figure 3. Topography of old/new differences from 300 to 800 ms after stimulus onset. $\boldsymbol{a}$, Midazolam condition. $\boldsymbol{b}$, Saline condition.

about the extent to which the FN400 is truly related to memory retrieval. The present results suggest that the FN400 (as measured through spatial PCA) did correlate with recognition memory performance, but only after midazolam administration. After saline, only the parietal old/new effect was correlated with recognition performance. This raises the intriguing possibility that subjects normally relied on recollection, but familiarity only made a substantial contribution to performance when recollection was suppressed. The present study conditions likely fostered high recollection rates (low-frequency words, 4 s study duration, semantic encoding task), so this pattern of recollection dominance would not necessarily apply to all situations.

It is important to consider the extent to which the present results may be spuriously related to factors other than the dualprocess distinction, such as confidence. The parietal old/new effect is known to encompass the P300 ERP component (Johnson, 1993; Spencer et al., 2000), and P300 amplitude increases with confidence (Hillyard et al., 1971; Wilkinson and Seales, 1978). Unlike the present results, in which midazolam interacted with parietal but not FN400 old/new differences, previous research has shown that confidence interacted with both effects (Curran, 2004), so the present drug effects cannot be reduced to confidence effects. Furthermore, the dual-process perspective predicts that confidence will affect the parietal response to only old items, because high confidence is characteristic of recollection and only old items can be recollected (Yonelinas, 2002). The generic P300 confidence perspective predicts that confidence should similarly affect the parietal response to both old and new items. Curran (2004) found that confidence affected the parietal responses to old items but not new items, as predicted by the dual-process perspective. Similarly, generic confidence should similarly affect old and new conditions in the present experiment, but drug effects were limited to the old condition. The P300 has been related to "context updating" (Donchin and Coles, 1988). Recollection can be conceptualized as involving context updating insofar as recollection mentally reinstates the context of the encoding episode, what Tulving (2002) has called "mental time travel." Thus, the observation that the parietal old/new effect encompasses the P300 component does not necessarily contradict the dualprocess perspective.

An ostensible limitation of the current study is the absence of behavioral estimates of recollection and familiarity, but we consider the use of a standard yes/no recognition test to be a strength rather than a weakness. Previous studies have manipulated the similarity of lures, varied the time allowed for subjects to make recognition judgments, or used estimation techniques such as the remember/know procedure or process dissociation procedure (Yonelinas, 2002). Many of these techniques have already been used in previous studies using ERPs (Rugg et al., 1998a; Curran, 2000, 2004; Nessler et al., 2001; Curran and Cleary, 2003) or midazolam (Hirshman et al., 2002; Mintzer et al., 2003) to study recollection and familiarity, and these provided the precedent for our hypotheses. However, the contribution of recollection to recognition-memory performance can be influenced by subjects' strategies and task instructions (Yonelinas, 1997; Rotello et al., 2000), and it has been suggested that familiarity holds sway under normal conditions, but recollection may be needed only in special situations such as when similar lures are tested (Hintzman and Curran, 1994; Malmberg et al., 2004a). Furthermore, critics of the dual-process perspective have argued that the measure- 


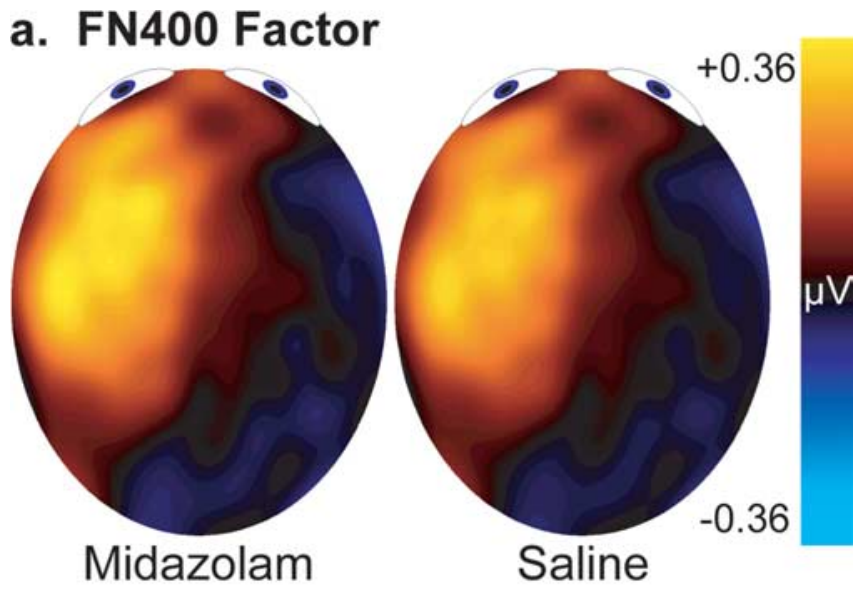

b. Parietal Factor

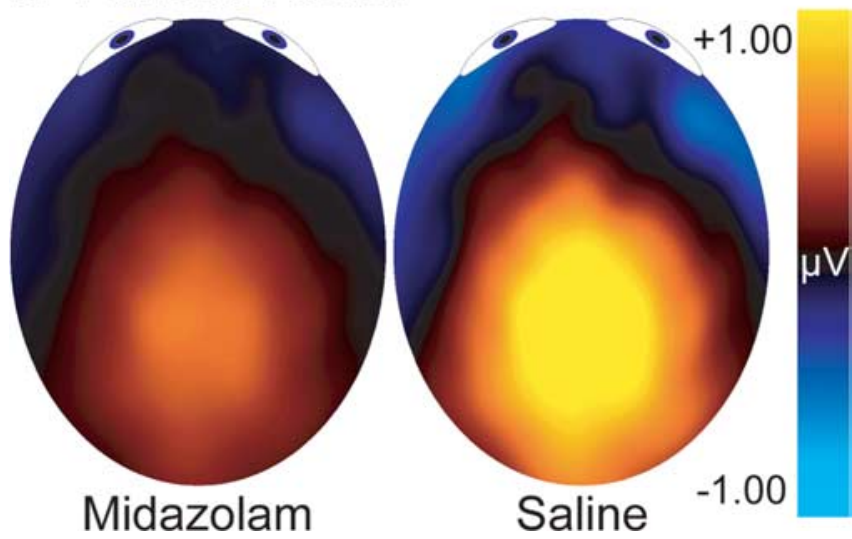

Figure 4. Topography of the PCA factors. The distribution of each factor is calculated by multiplying the factor loadings by the factor scores and then by the SDs for the original data. These values were averaged between 300 and 800 ms. $\boldsymbol{a}$, FN400 factor. $\boldsymbol{b}$, Parietal factor.
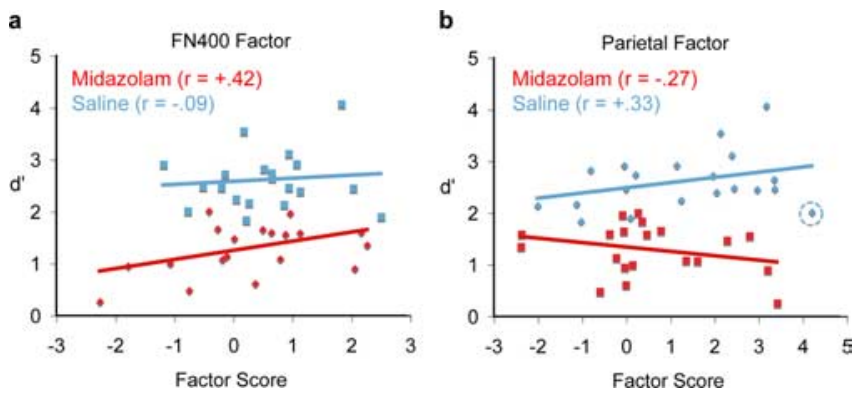

Figure 5. Correlations between accuracy $\left(d^{\prime}\right)$ and PCA factor scores. Each point represents a single subject in the saline (blue) or midazolam (red) condition. Lines are the best-fitting linear trends. $\boldsymbol{a}$, FN400 factor. $\boldsymbol{b}$, Parietal factor. The saline correlation increased when the circled observation was removed $(r=0.48)$.

ment of brain activity may provide convincing evidence for separate processes, but only if measured during standard paradigms rather than during special tasks that may unnaturally induce the engagement of recall-like processes (Humphreys et al., 2000). By using a standard yes/no recognition test, the present research provides convincing evidence for separate processes and suggests that recollection can be more strongly associated with recognition performance than is familiarity.

\section{References}

Curran T (2000) Brain potentials of recollection and familiarity. Mem Cognit 28:923-938.
Curran T (2004) Effects of attention and confidence on the hypothesized ERP correlates of recollection and familiarity. Neuropsychologia 42:1088-1106

Curran T, Cleary AM (2003) Using ERPs to dissociate recollection from familiarity in picture recognition. Brain Res Cogn Brain Res 15:191-205.

Curran T, Dien J (2003) Differentiating amodal familiarity from modalityspecific memory processes: an ERP study. Psychophysiology 40:979-988.

Curran T, Tepe KL, Piatt C (2006) ERP explorations of dual processes in recognition memory. In: Binding in human memory: a neurocognitive approach (Zimmer HD, Mecklinger A, Lindenberger U, eds). Oxford: Oxford UP, in press.

Dennis S, Humphreys MS (2001) A context noise model of episodic word recognition. Psychol Rev 108:452-478.

Dien J (1998a) Issues in the application of the average reference: reviews, critiques, and recommendations. Behav Res Methods Instrum Comput 30:34-43.

Dien J (1998b) Addressing misallocation of variance in principal components analysis of event-related potentials. Brain Topogr 11:43-55.

Donaldson W (1996) The role of decision processes in remembering and knowing. Memory Cognit 24:523-533.

Donchin E, Coles M (1988) Is the P300 component a manifestation of context updating? Behav Brain Sci 11:357-374.

Dunn JC (2004) Remember-know: a matter of confidence. Psychol Rev 111:524-542.

Düzel E, Vargha-Khadem F, Heinze H-J, Mishkin M (2001) Brain activity evidence for recognition without recollection after early hippocampal damage. Proc Natl Acad Sci USA 98:8101-8106.

Eldridge LL, Knowlton BJ, Furmanski CS, Bookheimer SY, Engel SA (2000) Remembering episodes: a selective role for the hippocampus during retrieval. Nat Neurosci 3:1149-1152.

Evans MS, Viola-McCabe KE (1996) Midazolam inhibits long-term potentiation through modulation of GABAA receptors. Neuropharmacology 35:347-357.

Feldman RS, Meyer JS, Quenzer LF (1997) Principles of neuropsychopharmacology. Sunderland, MA: Sinauer.

Frank MJ, O'Reilly RC, Curran T (2006) When memory fails, intuition reigns: midazolam enhances implicit inference in humans. Psychol Sci, in press.

Friedman D, Johnson Jr R (2000) Event-related potential (ERP) studies of memory encoding and retrieval: a selective review. Microscopy Res Tech 51:6-28.

Gonsalves BD, Kahn I, Curran T, Norman KA, Wagner AD (2005) Memory strength and repetition suppression: multimodal imaging of medial temporal cortical contributions to recognition. Neuron 47:751-761.

Henson RN, Cansino S, Herron JE, Robb WG, Rugg MD (2003) A familiarity signal in human anterior medial temporal cortex? Hippocampus 13:301-304.

Hillyard SA, Squires KC, Bauer JW, Lindsay PH (1971) Evoked potential correlates of auditory signal detection. Science 172:1357-1360.

Hintzman DL, Curran T (1994) Retrieval dynamics of recognition and frequency judgments: evidence for separate processes of familiarity and recall. J Mem Lang 33:1-18.

Hirshman E, Master S (1997) Modeling the conscious correlates of recognition memory: reflections on the remember-know paradigm. Mem Cognit 25:345-351.

Hirshman E, Fisher J, Henthorn T, Arndt J, Passannante A (2002) Midazolam amnesia and dual-process models of the word-frequency mirror effect. J Mem Lang 47:499-516.

Humphreys MS, Dennis S, Chalmers KA, Finnigan S (2000) Dual processes in recognition: does a focus on measurement operations provide a sufficient foundation? Psychon Bull Rev 7:593-603.

Jacoby LL (1991) A process dissociation framework: separating automatic from intentional uses of memory. J Mem Lang 30:513-541.

Johnson Jr R (1993) On the neural generators of the P300 component of the event-related potential. Psychophysiology 30:90-97.

Joordens S, Hockley WE (2000) Recollection and familiarity through the looking glass: when old does not mirror new. J Exp Psychol Learn Mem Cogn 26:1534-1555.

Junghöfer M, Elbert T, Tucker DM, Braun C (1999) The polar average reference effect: a bias in estimating the head surface integral in EEG recording. Clin Neurophysiol 110:1149-1155.

Kobayashi S, Fujito Y, Matsuyama K, Aoki M (2004) Differential effects of 
midazolam on inhibitory postsynaptic currents in CA1 pyramidal cells and dentate gyrus granule cells of rat hippocampal slices. Brain Res 1003:176-182.

Kobayashi S, Fujito Y, Matsuyama K, Aoki M (2005) Comparison of midazolam effects on inhibitory postsynaptic currents in hippocampal CA3 with those in CA1. NeuroReport 16:1003-1007.

Kucera H, Francis WN (1967) Computational analysis of present-day American English. Providence, RI: Brown UP.

Malmberg KJ, Holden JE, Shiffren RM (2004a) Modeling the effects of repetitions, similarity, and normative word frequency on old-new recognition and judgments of frequency. J Exp Psychol Learn Mem Cogn 30:319-331.

Malmberg KJ, Zeelenberg R, Shiffrin RM (2004b) Turning up the noise or turning down the volume? On the nature of the impairment of episodic recognition memory by midazolam. J Exp Psychol Learn Mem Cogn 30:540-549.

Mecklinger A (2000) Interfacing mind and brain: a neurocognitive model of recognition memory. Psychophysiology 37:565-582.

Mintzer MZ, Griffiths RR, Hirshman E (2003) A paradoxical dissociation in the effects of midazolam on recollection and automatic processes in the process dissociation procedure. Am J Psychol 116:213-237.

Montpied P, Martin BM, Cottingham SL, Stubblefield BK, Ginns EI, Paul SM (1988) Regional distribution of the $\mathrm{GABA}_{\mathrm{A}}$ /benzodiazepine receptor (alpha subunit) mRNA in rat brain. J Neurochem 51:1651-1654.

Nessler D, Mecklinger A, Penney TB (2001) Event related brain potentials and illusory memories: the effects of differential encoding. Brain Res Cogn Brain Res 10:283-301.

Nessler D, Mecklinger A, Penney TB (2005) Perceptual fluency, semantic familiarity and recognition-related familiarity: an electrophysiological exploration. Brain Res Cogn Brain Res 22:265-288.

Norman KA, O'Reilly RC (2003) Modeling hippocampal and neocortical contributions to recognition memory: a complementary learning systems approach. Psychol Rev 110:611-646.

Olichney JM, Petten Cv, Paller KA, Salmon DP, Iragui VJ, Kutas M (2000) Word repetition in amnesia: electrophysiological measures of impaired and spared memory. Brain 123:1948-1963.

Picton TW, Lins OG, Scherg M (1995) The recording and analysis of eventrelated potentials. In: Handbook of neuropsychology (Boller F, Grafman J, eds), pp 3-73. Amsterdam: Elsevier.

Picton TW, Bentin S, Berg P, Donchin E, Hillyard SA, Johnson Jr R, Miller GA, Ritter W, Ruchkin DS, Rugg MD, Taylor MJ (2000) Guidelines for using human event-related potentials to study cognition: recording standards and publication criteria. Psychophysiology 37:127-152.

Polster M, McCarthy R, O'Sullivan G, Gray P, Park G (1993) Midazolaminduced amnesia: implications for the implicit/explicit memory distinction. Brain Cogn 22:244-265.

Ratcliff R, Van Zandt T, McKoon G (1995) Process dissociation, single- process theories, and recognition memory. J Exp Psychol Gen 124:352-374.

Reder LM, Nhouyvanisvong A, Schunn CD, Ayers MS, Angstadt P, Hiraki K (2000) A mechanistic account of the mirror effect for word frequency: a computational model of remember-know judgments in a continuous recognition paradigm. Exp Psychol Learn Mem Cogn 26:294-320.

Reinsel RA, Veselis RA, Dnistrian AM, Feshchenko VA, Beattie BJ, Duff MR (2000) Midazolam decreases cerebral blood flow in the left prefrontal cortex in a dose-dependent fashion. Int J Neuropsychopharmacol 3:117-127.

Rotello CM, Macmillan NA, Van Tassel G (2000) Recall-to-reject in recognition memory: evidence from ROC curves. J Mem Lang 43:67-88.

Rugg MD, Yonelinas AP (2003) Human recognition memory: a cognitive neuroscience perspective. Trends Cogn Sci 7:313-319.

Rugg MD, Schloerscheidt AM, Mark RE (1998a) An electrophysiological comparison of two indices of recollection. J Mem Lang 39:47-69.

Rugg MD, Mark RE, Walla P, Schloerscheidt AM, Birch CS, Allan K (1998b) Dissociation of the neural correlates of implicit and explicit memory. Nature 392:595-598.

Shiffrin RM, Steyvers M (1997) A model of recognition memory: REMretrieving effectively from memory. Psychol Bull Rev 4:145-166.

Spencer KM, Vila Abad E, Donchin E (2000) On the search for the neurophysiological manifestation of recollective experience. Psychophysiology 37:494-506.

Srinivasan R, Nunez PL, Silberstein RB, Tucker DM, Cadusch PJ (1996) Spatial sampling and filtering of EEG with spline-Laplacians to estimate cortical potentials. Brain Topogr 8:355-366.

Tucker DM (1993) Spatial sampling of head electrical fields: the geodesic sensor net. Electroencephalogr Clin Neurophysiol 87:154-163.

Tulving E (2002) Episodic memory: from mind to brain. Annu Rev Psychol 53:1-25.

Wheeler ME, Buckner RL (2004) Functional-anatomic correlates of remembering and knowing. NeuroImage 21:1337-1349.

Wilkinson RT, Seales DM (1978) EEG event-related potentials and signal detection. Biol Psychol 7:13-28.

Yonelinas AP (1997) Recognition memory ROCs for item and associative information: the contribution of recollection and familiarity. Memory Cognit 25:747-763.

Yonelinas AP (2002) The nature of recollection and familiarity: a review of 30 years of research. J Mem Lang 46:441-517.

Yonelinas AP, Otten LJ, Shaw KN, Rugg MD (2005) Separating the brain regions involved in recollection and familiarity in recognition memory. J Neurosci 25:3002-3008.

Yovel G, Paller KA (2004) The neural basis of the butcher-on-the-bus phenomenon: when a face seems familiar but is not remembered. NeuroImage 21:789-800. 